present time she has better health than she has had for the last two years.

In anæmia I have been greatly struck by the action of plasmon. Two of the cases were very severe in character, extreme breathlessness on the slightest exertion, palpitation, tinnitus, and a syncopic tendency being present. The rapidity of the improvement in these cases under rest, iron, and plasmon dissolved in milk (one drachm in half a pint of milk three or four times a day) was simply marvellons when compared with other cases similarly treated, but without the plasmon.

The case of puerperal septicæmia was that of a woman who was confined of her second child on June 18tb, 1900. On July 1st she had a rigor; her temperature rose to $104.5^{\circ} \mathrm{F}$. during the next few days, and she had several rigors more or less severe. On the 6th she had a very severe rigor and was violently sick; her tempera ure at 10 A.M. was $105.2^{\circ}$. She was put upon plasmon which agreed perfectly with her, and in the afternoon she seemed greatly better and ihe temperature had fallen to $103^{\circ}$. On the next morning it was $99 \cdot 4^{\circ}$ on the following day it was normal and her convalescence was uninterrupted. The probable canse of the septicæmia in this case was a block in a faulty drain and insanitary conditions arising therefrom, which had in the meantime been rectified.

A woman, aged 32 years, started with severe erysipelas of the head, the neck, and the chest on July 3rd, 1900. This was followed by a large abscess formation over the right infraclavicular region which extended half way down the sternum, which was opened and drained on the 15th. After this the temperature fell and the appetite improved. On the 18th she was very sick and complained that all things disagreed with her and the temperature rose again. On that day she was put on plasmon, which at once seemed to suit her, and there were no further drawbacks.

In the cases of tuberculous diarrhcea, all of which were unfortunately in an advanced stage, plasmon most distinctly gave great relief; the diarrhœa was greatly lessened, the temperature was kept much lower, and the abdominal pain and distension were relieved. That life was considerably prolonged those who saw the cases were convinced, and they could not help thinking that had it been used in the early stages the prognosis of the cases might have been hopeful

In the cases of acute diarrhœea plasmon answered well. One of them was an old lady, aged 92 years, suffering from bronchitis at the time and whose case seemed hopeless. She was kept for several weeks upon it and is now as well as she has been for the last three years, getting up daily in her bedroom.

It seems particularly good in neurasthenic cases and builds up the nervous system. Two of the cases of gastric neurasthenia had been for years under treatment, one under my care for four years and the other for two years and prior to that constantly under the care of other medical men and for some months now the patients have been off my list and have had no medicine at all.

Personally I have used plasmon considerably, chiefly in the form of the chocolate and the biscuits, which I carried the whole of last winter on hunting days, as did several hunting friends, also on long days' shooting on the moors in Scotland and fishing in Yorkshire; and I have always found that I could stand the longest day with less fatigue for the moment and less feeling of exhaustion afterwards than formerly. One hunting friend. who has also a pack of beagles which he hunts himself on foot, told me that he always carries the chocolate now and that constant consignments of the chocolate have been sent out to three of his brothers who are at present serving in South Africa.

When at Aldershot this Whitsuntide I thought it would be a good opportunity of trying its sustaining properties and I had some sent down for the officers' mess. On the unfortunate Monday which will always be remembered at Aldershot as "Black Monday" all our officers, 23 in number, carried three sticks of plasmon chocolate; none of us suffered the slightest either from the heat or from the fatigue, and although we had breakfast at 5.30 A.M. and did not messuntil 8 P.M., one of the senior captains told me that, with the exception of the chocolate and a drink of lime-juice and soda, he had absolutely nothing between times, that he felt quite fresh, and had no feeling of exhaus. tion.

So far I have not found a single patient object to it and being practically tasteless it can be added to other foods without destroying their natural flavour, thus allowing it to be given without detection-a property of material advantage when one has to deal with faddy patients.

What has struck me most in using plasmon is the ease with which it is digested and the variety of media in which it can be used; preferably in my own practice I use milk, animal broths, or barley-water. The majority of patients like it and express a feeling of comfort and well-being after taking it, and their rapid gain of weight is most marked. One of our nurses at the workbouse who was run down and anæmic, taking nothing in addition to her ordinary diet but a full teaspoonful of plasmon dissolved in half a pirt of milk twice daily, gained three pounds in weight in a fortnight.

Since compiling these notes 1 have seen Captain who has returned from South Africa, one of the three brothers previously alluded to; his stalement as to the use of plasmon chocolate I give in his own words: "It was splendid stuff-quite the best thing we had out there. I sent home for some more."

Otley, Yorks.

\section{ESTIMATION OF IRON IN ANIMAL ORGANE.}

BY PERCY A. E. RICHARDS, F.I.C.,

ASSISTANT LECTURER ON CHEMISTRY AND PHYSICS, CHARIXG-CROSS HOSPITAL MEDICAL SOHOOL, AND PUBLIO ANALYST TO THE PARISH OF ST. MARIIN-IN-THE-FIELDS.

THE amount of iron in human viscera is often a matter of considerable importance to the pathologist, but although that metal can be easily and accurately estimated, when present in any distinct quantity, by ordinary gravimetric methods, yet in the particular cases under consideration such a process frequently fails to give concordant results. This is due primarily to the small proportion of iron usually found in animal organs and also indirectly to the insoluble phosphates that are invariably present. A gravimetric method necessitates careful elimination of these during the process of estimation and it also entails the employment of a large amount of the organ for each operation. With a view to meeting these objections as far as possible the following process has been devised and has given most satisfactory results in practice.

From 50 grammes to 100 grammes of the moist organ are weighed in a platinum dish and heated over a Bünsen burner until all moisture is driven off, the organic matter is burnt, and only a black, charred mass remains. This is carefully moistened throughout with strong nitric acid, avoiding a large excess, and is then incinerated gently to prevent loss during deflagration. The great bulk of the carbon may thus be removed, the mass being treated a second time with acid if required and again incinerated thoroughly. It is, perhaps, hardly necessary to point out that the nitric acid should be previously tested to ensure its freedom from iron. The metal is now left behind with the other mineral matter and a small amount of carbon. This is treated with pure hydrochloric acid, is allowed to stand for five minutes, and is then warmed and transferred to a beaker. The basin is washed out with warm hydrochloric acid, the washings are added to the bulk, and the whole is boiled after the addition of a few drops of strong nitric acid. This ensures thorough oxidation, and neglect of this precantion involves possible inaccuracy due to the presence of ferrous, with the bulk of ferric, iron. The solution after boiling is diluted with an equal volume of water and is filtered, the residue is washed with hot water, and the filtrate is made up to 50 or 100 cubic centimetres. This forms the stock solution and from it a measured portion (from one to 20 cubic centimetres, according to the strength of the solution) is taken with the pipette and is transferred to a Nessler glass. To this is added one cubic centimetre of a freshly-prepared solution of potassium ferrocyanide (1 per cent.) and the mixture is at once made up to 50 cubic centimetres. If precipitation occurs or if the colour is too intense the portion should be rejected and a smaller quantity of the stock solution taken. The colour so obtained is matched against that given by a known quantity of a standard iron solution and the weight of the metal is thence found by calculation. A suitable iron standard is one con. taining 0.1 gramme of metal per litre, each cubic centimetre being then equivalent to $0.0001 \mathrm{Fe}$. Such a standard is 
best prepared by accurately weighing out 0.1 gramme of the purest "flower" wire, dissolving this in the minimum amount of hydrochloric acid, oxidising the hot solntion with nitric acid, added drop by drop, boiling off the excess of the latter, and finally making up with distilled water to one litre.

If desired the estimation as detailed above may be repeated, using sulphocyanide of potash in place of ferrocyanide, the red ferric sulphocyanide being formed in place of the blue ferric ferrocyanide. In this case greater care must be taken to prevent the presence of much nitric acid, which itself gives a red colour with the sulphocyanide and would hopelessly vitiate the results.

Another matter of considerable practical importance is the accurate estimation of the moisture, as the results obtained above should be expressed in terms of dry viscera. Any attempt at removing the whole of the moisture from the weight necessary for the iron determination is both tedious and imperfect. It is therefore best to cut off a small piece of the organ at the time that a larger amount is taken, to place this in a separate dish, to divide it into small, thin slices with a sharp knife, to weigh, and to dry thoroughly in a water oven, and weigh again. The percentage of moisture can thus be accurately found.

The organs chiefly examined consisted of the liver, the kidney, and the spleen, and with all these the process has given good and concordant results.

Ohemical Laboratory, Oharing-cross Hospital.

\section{a dithror}

\section{or}

\section{HOSPITAL PRACTICE, BRITISH AND FOREIGN.}

Fulia autem est alia pro certo noscendi via, nisl quamplurimas et morborum et dissectionum historias, tum aliorum tum propria collectas habere, et inter se comparare.-MoRGAGI De Sed. et Caus. collectas habere, et inter
Morb., lib. iv. Procemium.

\section{MILLER HOSPITAL, GREENWICH.}

A OASE OF PERFORATING GASTRIC ULCER.

(Under the care of the late Mr. T. Moorm.)

THE fact that there was a thick layer of lymph on the surface of the stomach, together with the escape of much gas on opening the peritoneal cavity, prove fairly conclusively that in this case a perforation must have occurred, though it is probable that very little extravasation took place, and that the opening was rapidly closed by effused lymph. For the notes of the case we are indebted to Mr. R. S. C. Edleston, late house surgeon.

A woman, aged 22 years, a general servant, was admitted into the Miller Hospital at 10 P.M. on Oct. 19th, 1899, with symptoms of perforation of gastric ulcer. Six months previously the patient was treated by Dr. W. Groome for anæmia and apparently completely recovered and retarned to work. She admitted having been rather breathless on exertion, but she had never suffered from pain after taking food or at any time until the evening of Oct. 18th, when she was suddenly seized with violent pain in the abdomen. The pain continued throughout the night and she vomited once. On the following morning the pain had abated and she took an egg and bread-and-butter for breakfast, after which the pain almost immediately returned and was very severe, and she again vomited. Dr. Groome was called in and the patient was ordered to have milk and soda-water only and she did not vomit again until shortly before her removal to the hospital, to which she was conveyed on an ambulance.

On admission the patient appeared to be in great agony. The pulse was 146 , the respirations were 52 , and the temperature was $103^{\circ} \mathrm{F}$. The face was pale and the expression was anxions. The eyes were widely open and staring. The lips and the tongue were dry. She was retching continuously, but did not vomit. The abdomen was greatly distended and tympanitic, it was tender all over, but especially in the region of the ensiform cartilage. Mr. Moore, who saw the patient at 11 P.M., concurred in the diagnosis of perforated gastric ulcer and it was decided to open the abdomen without delay.

An incision was made under chloroform from the ensiform cartilage to the umbilicus. On opening the abdominal cavity (which was reached with considerable difficulty owing to the distension and matting together of the tissues) gas escaped freely. A layer of organised lymph having been turned up the anterior surface of the stomach was exposed, and just below the lesser curvature midway between the cardiac and pyloric ends three elevated and dusky spots were seen lying close together, and each of about the size of a sixpenny-piece; the layer of lymph immediately covering them was almost as thick as the palm of the hand. There was no evidence of perforation, the peritoneal fluid, though plentiful, being quite clear. The stomach was firmly fixed by adhesions and consequently its under surface could not be examined. The abdominal cavity was thoroughly washed out with a weak solution of boric acid in boiled water and the layer of lymph was carefully replaced over the affected area. Owing to the peritoneal adhesions the whole length of the peritoneal wound could not be accurately united by continuous suture and several fine interrupted silk sutures had to be put in. The abdominal wall was united by stout salmon-gut sutures, no drainage-tube being used. The patient made an effort to vomit at the completion of the suturing of the abdominal wound.

On Oct. 20th no vomiting had occurred since the operation. The pulse was 98 , the temperature was $101^{\circ}$, and the respira. tions were 34 . One pint of water was given by the rectum; only teaspoonfuls of water were given by the mouth. On the 22nd four-ounce pancreatised nutrient enemata were given every four hours, and the rectum was washed out with one pint of warm water containing 20 grains of sodium bicarbonate half an hour before each nutrient enema. On the 23rd the patient complained of severe thirst, and milk and water, half an ounce of each, were given every three hours. On the 24th the milk and water were increased to two ounces every three hours. Nutrient enemata were given as before. The patient slept well and suffered no discomfort, but as the temperature was oscillating, though it was never high, the wound was dressed, and there was a slight purulent discharge from the suture wounds at the upper and lower end of the wound; the lowest suture was removed. On the 25 th the diet was altered, two ounces of mutton-broth being given alternately with two ounces of milk and water every three hours. On the 28th the wound was dressed and a large quantity of purulent discharge occurred from both points above mentioned. The lower part of the wound was freely opened and a drainage-tube was put in, the wound being gently syringed out with boric lotion. On the 30 th the wound was dressed twice daily. On Nov. Ist there was less discharge and the upper part of the wound was healed. The diet con. sisted of three onnces each of beef-tea or mutton-broth alternately with three ounces of milk and one ounce of limewater. The enemata were discontinued. On the 5th the wound was firmly healed except where the tube was put in. The food was the same as on Nov. 1st, but was increased to six ounces at a time. On the 8th one drachm of virol was giren three times a day after food. The food was the same as above but was increased to eight ounces every three hours. On the 11th two eggs daily were added to the diet, one with the milk and one as a custard pudding. On the 13th only a small button-hole was left where the drainage-tube had been removed. The virol was increased to two drachms three times a day. The patient was putting on flesh and was gaining colour. On the 20 th a small granulation which had taken the place of the button-hole at the lower part of the wound was touched with silver nitrate. On Dec. 1st the wound was firmly healed. The virol was suspended. On the 5th the virol was again given as the patient did not seem to get on so well without it. On the 17th the patient was taking three drachms of virol three times a day and was putting on flesh and looked much better. She was given pounded fish and chicken. On the 19th she sat np for half an hour in the evening. On the 25th she was sitting up half the day. On the 28th she got up all day and walked about the ward. On Jan. 2nd, 1900, she left the hospital for a convalescent home, taking a supply of virol with ber and was now taking half an ounce three times a day after food. On the 26th she returned from the convalescent home strong and healthy. Virol suited this patient and she digested it well. 